\title{
A ESPACIALIZAÇÃO E A TERRITORIALIZAÇÃO DAS ESCOLAS DE ENSINO MÉDIO DO CAMPO EM ASSENTAMENTOS DE REFORMA AGRÁRIA: CONSTRUÇÃO COLETIVA E EM MOVIMENTO NO CEARÁ
}

\author{
Spatialization and territorialization of secondary education field schools in agrarian reform \\ settlements: collective and ongoing construction in Ceará
}

Cinira Ricardo Cordeiro*

Marize Luciano Vital M. de Oliveira**

* Mestranda em Geografia na UVA - cinira geografia@hotmail.com. ** Professora do Mestrado em Geografia da UVA - marizevital@gmail.com.

Recebido em 17/08/2018. Aceito para publicação em 03/09/2018.

Versão online publicada em 20/11/2018 (http://seer.ufrgs.br/paraonde)

\begin{abstract}
Resumo: 0 presente trabalho é fruto de uma pesquisa de mestrado e tem como objetivo central analisar a educação do campo no estado do Ceará, tendo como objeto a escola de ensino médio do campo dos assentamentos de reforma agrária do Movimento dos Trabalhadores Rurais Sem Terra. Procuramos contribuir para o debate do tema a partir da luta dos movimentos sociais na construção da educação do campo, um novo conceito e uma nova proposta que se contrapõem ao modelo hegemônico de educação vigente. Portanto, um fenômeno recente, em construção coletiva e em movimento no País e no Ceará.
\end{abstract}

Palavras-chave: Educação do Campo. Escola do Campo. Territorialização.

\begin{abstract}
The present work is the result of a research for a master's thesis and it has as its central goal to analyze field education in the state of Ceará and whose object is the field secondary school at the agrarian reform settlements from the Landless Rural Workers' Movement (MST). We sought to contribute to the debate over this theme from the struggle of the social movements in the construction of field education, a new concept and a new proposal which oppose to the current hegemonic education model. Therefore, it is a recent phenomenon in collective and ongoing construction in the country and in Ceará.
\end{abstract}

Key-words: Field Education; Field School; Territorialization.

\section{1 - Introdução}

A partir de meados da década de 1980, as demandas dos movimentos sociais organizados do campo se fortalecem e, ao lado da luta pela terra, passam a se dedicar ao direito à educação, exigindo do Estado brasileiro políticas públicas que atendam às necessidades dos camponeses, destacando-se a atuação dos assentamentos de reforma agrária do Movimento dos Trabalhadores Rurais Sem Terra (MST). Nasce, portanto, uma nova educação para o campo: um fenômeno recente, em construção coletiva e em movimento no País e no Ceará. Procurando contribuir para o debate do tema, buscamos identificar, na luta dos movimentos sociais, desafios, limites e conquistas que buscam a construção da educação para o campo, que se contrapõe ao modelo de educação do Brasil. No Ceará, a análise e a compreensão da construção dessa educação acontecem a partir dos processos que a originam e cuja materialização se dá com a conquista das escolas do campo de ensino médio. As escolas em assentamentos de reforma agrária são símbolos da luta por educação e melhoria da vida no campo, visto que educar os camponeses é uma das maneiras de alcançar melhorias. Nesse contexto, a questão principal passa pelo conhecimento do território e da base teórica e prática para transformar e melhorar a realidade nos assentamentos. As escolas do campo têm importante papel nessa conjuntura, uma vez que seus princípios e fundamentos são pautados na pedagogia do movimento, com base na luta por 
justiça social, sendo fortemente influenciada pelas contribuições de Paulo Freire (1987), com a educação popular; e, recentemente, pelas contribuições teóricas de Caldart (2008, 2012), Freitas (2013), Kolling (2002), Molina (2006) e Orso (2013).

Assim, buscamos uma aproximação teórica com o caso do Ceará, cujo processo de luta por educação do campo tem como marco a conquista das escolas de ensino médio do campo, as quais, para os educadores e educadoras, têm como grande desafio pedagógico serem assumidas pelos sujeitos que a conquistaram. Aqui ressaltamos as identidades dos/as educadores/as com a proposta de educação do campo e a importância das formações deles, exigindo mudanças teóricas e metodológicas, criando e construindo em um movimento constante e permanente. A partir da luta do MST junto ao governo estadual do Ceará, foi assegurada a construção de 12 escolas de ensino médio, todas espacialmente localizadas em assentamentos de reforma agrária. Dessas, duas escolas foram construídas e se encontram em funcionamento desde 2011 nos municípios de Itarema e Itapipoca, no litoral cearense. No Noroeste do sertão cearense, sete escolas foram garantidas, das quais três tiveram suas atividades iniciadas também em 2011 e duas em 2016, estando localizadas nos municípios de Canindé, Madalena, Monsenhor Tabosa e Santana do Acaraú. No Sertão Central, duas escolas estão em fase de finalização da construção nos municípios de Quixeramobim e Mombaça, e uma nas proximidades da Região Metropolitana de Fortaleza, no município de Ocara foi finalizada e entrou em funcionamento do segundo semestre de 2017 (Figura 1).

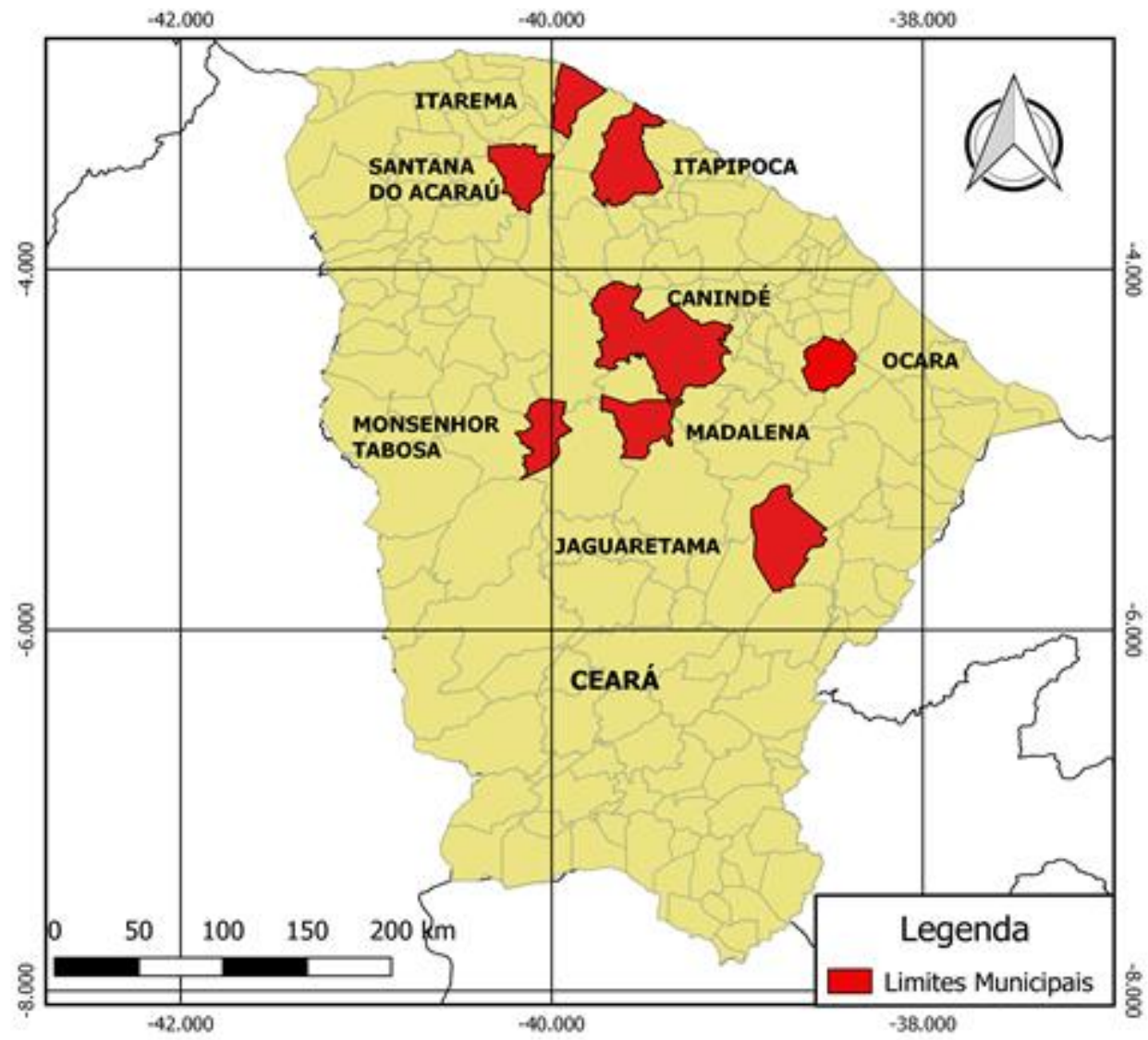

Figura 1 - Espacializaçaõ das EEM do Campo no Ceará (2017)

\section{2 - A luta por educação do campo e a construção do conceito}

Na década de 1980, no final da ditadura militar, nasce o MST, movimento social que desponta tendo como questão central a luta por terra para plantar e viver. Mas, em meio às primeiras ocupações, nos acampamentos emerge a necessidade e o começo de um novo desafio, o de educar os/as filhos/as dos/as camponeses/as que estavam embaixo das lonas pretas. Portanto, a luta por educação acontece 
simultaneamente à luta por terra. Esse processo de educação se inicia com a educação na infância, como afirmam Kolling, Vargas e Caldart (2012, p. 502):

A educação entrou na agenda do Movimento dos Trabalhadores Rurais Sem Terra (MST) pela infância. Antes mesmo da sua fundação, ocorrida em 1984, as famílias sem terra, acampadas na Encruzilhada Natalino, Rio Grande do Sul (1981), perceberam a educação da infância como uma questão, um desafio.

A continuidade da luta do MST "por uma educação do campo" desde a década de 1980 até os dias atuais foi sendo construída com o objetivo de escolarização e formação nos três níveis de ensino: educação infantil, educação básica e educação superior para a classe trabalhadora.

Em 1996, a Lei de Diretrizes e Bases da Educação Nacional (LDB) - aprovada como lei no 9.394, de 20 de dezembro do referido ano - torna-se basilar para o avanço da educação do campo como um direito de todos e dever do Estado. Já em 1997, desponta o I Encontro de Educadoras e Educadores da Reforma Agrária (ENERA), grande e importante evento fruto da organização e mobilização do MST, como afirmam Fernandes e Molina (2004, p. 11):

A ideia de Educação do Campo nasceu em julho de 1997, quando da realização do Encontro Nacional de Educadoras e Educadores da Reforma Agrária - ENERA, no campus da Universidade de Brasília - UnB, promovido pelo Movimento dos Trabalhadores Rurais Sem Terra - MST, em parceria com a própria UnB, o Fundo das Nações Unidas para a Infância - UNICEF, a Organização das Nações Unidas para Educação, Ciência e Cultura - UNESCO e a Conferência Nacional dos Bispos do Brasil - CNBB.

Influenciada pela mídia brasileira, a grande maioria da população brasileira que não conhece profundamente o MST - esse imenso movimento que atua na maioria dos estados do Brasil - criou uma definição negativa sobre essa organização social. Contudo, como afirma Stédile (2012, p. 76), "para os meios de comunicação, para a sociedade em geral, o ENERA ajudou a propagandear, no sentido positivo, que o MST não se preocupa só com terra; se preocupa também com escola, com educação".

Lutar por educação é tentar garantir um direito de todos os cidadãos. Quando esse direito não é estendido aos povos do campo, é necessária a mobilização do MST em parceria com a população e o apoio de instituições para que essa luta possa avançar.

A realização do I ENERA proporcionou bases para a criação e consolidação do Programa Nacional de Educação na Reforma Agrária (PRONERA), outra conquista da luta do MST e dos povos do campo em parceria com várias universidades do país, proporcionando educação para vários assentados do Brasil. O PRONERA nasceu em 1998, sendo assim definido:

O Programa Nacional de Educação na Reforma Agrária (PRONERA) é uma política pública de Educação do Campo, desenvolvida nas áreas de reforma agrária e executada pelo Instituto Nacional de Colonização e Reforma Agrária INCRA, no âmbito do Ministério do Desenvolvimento Agrário (MDA). Seu objetivo é fortalecer as áreas de Reforma Agrária como espaços de vida em todas as suas dimensões: econômicas, sociais, educacionais, políticas e culturais. 0 PRONERA nasceu em 1998 da luta dos movimentos sociais e sindicais do campo. Desde então, milhares de jovens e adultos, trabalhadores das áreas de reforma agrária têm garantido o direito de alfabetizar-se e de continuar os estudos em diferentes níveis e modalidades de ensino. (BRASIL, 2016, p. 8).

A criação do PRONERA faz parte do percurso de luta por educação pública, gratuita e de qualidade para os camponeses. Esse programa possibilitou que vários jovens e adultos fossem alfabetizados. O programa é criado em 1998 e se torna política pública em 2010, com o Decreto no 7.352.

O PRONERA é uma política pública de Educação do Campo, instituída pelo Decreto n.o 7.352, de 04 de novembro de 2010. Seu objetivo é desenvolver 
projetos educacionais de caráter formal, a serem executados por instituições de ensino, para beneficiários do Plano Nacional de Reforma Agrária (PNRA), do Crédito Fundiário, e dos projetos feitos pelos órgãos estaduais, desde que reconhecidos pelo Incra. O PRONERA é executado pelo Incra Sede, em Brasília (DF), e por suas respectivas Superintendências Regionais (SRs). (BRASIL, 2016, p. 13).

Por meio dos projetos desenvolvidos pelo PRONERA, muitos/as camponeses/as atualmente ingressam em universidades, uma conquista que não veio facilmente, sendo conquistada arduamente por meio da luta por educação do campo, construída e transformada em política pública.

O movimento de educação do campo inicia-se com a nomenclatura de educação básica do campo, mas, assim como qualquer pessoa que more na cidade ou no campo, os povos do campo merecem educação do/no campo, tendo a opção de ir além da educação básica, ingressando em uma universidade. Sobre o surgimento dessa expressão, Caldart (2012, p. 259) considera que:

O surgimento da expressão 'Educação do Campo' pode ser datado. Nasceu primeiro como Educação Básica do Campo no contexto de preparação da I Conferência Nacional por uma Educação Básica do Campo, realizada em Luziânia, Goiás, de 27 a 30 de julho 1998. Passou a ser chamada Educação do Campo a partir das discussões do Seminário Nacional realizado em Brasília de 26 a 29 de novembro 2002, decisão posteriormente reafirmada nos debates da II Conferência Nacional, realizada em julho de 2004.

Conquistar educação básica é um desejo dos povos do campo, mas, em busca da qualidade de vida e por meio da leitura da realidade, são perceptíveis os anseios dos camponeses também por educação superior nas áreas de reforma agrária, que conquistaram o ensino superior por meio do curso superior em Educação do Campo. 0 processo vai se consolidando, e a mudança de expressão para "educação do campo" torna-se mais que uma simples nomenclatura, definindo teoricamente os anseios reais dos povos do campo.

A educação do campo se converte na evidência da insatisfação popular dos camponeses e na decisiva luta dos movimentos sociais por direito à educação, sendo garantida em lei e estando pautada em uma tríade campo - politica pública - educação, como afirma Caldart (2008, p. 70):

A materialidade de origem (ou de raiz) da educação do Campo exige que ela seja pensada/trabalhada sempre na tríade: Campo - Política Pública - Educação. É a relação, na maioria das vezes tensa, entre estes termos que constitui a novidade histórica do fenômeno que batizamos de Educação do Campo [...].

Essa relação entre o campo, a política pública e a educação deve estar sempre presente, pois o primeiro termo da tríade (campo) é um território dinâmico, formado por pessoas que possuem anseios e direitos; enquanto que a educação é um direito desses povos do campo. Os povos que vivem no campo lutam por escola do campo para permanecer no seu lugar de origem e, assim, não serem expropriados de sua cultura e identidade campesina.

As necessidades dos povos do campo e sua luta por direitos muitas vezes negados gerou a mobilização do MST junto aos povos do campo em busca de políticas públicas para, assim, garantir uma educação do/no campo gratuita e de qualidade. A luta contínua e em movimento assegura a conquista e existência do PRONERA, da educação em diferentes níveis e modalidades e de outras políticas setoriais voltadas aos assentamentos de reforma agrária.

Na tríade, a educação, fundada na necessidade de educar os filhos e as filhas de acampados/as é fruto de muitas reflexões, de muitos debates e da união dos povos do campo. Tal educação é possuidora de fundamentos e adota os princípios educativos do trabalho, da cultura, das lutas sociais, da organização coletiva e da história. 
Portanto, o movimento "Por uma Educação do Campo" é resultado da crise de valores e relevância que envolveu o mundo das organizações dos trabalhadores na década de 1990 e das novas e positivas formas de organização popular no campo.

\title{
2.1 - A educação do campo no Ceará: construção coletiva e territorialização das EEM do Campo
}

No Ceará, a luta por educação do campo do Movimento dos Trabalhadores Rurais Sem Terra (MST) se insere no contexto das lutas do campo no Brasil, nos últimos 30 anos.

\begin{abstract}
De um lado, o projeto da Agricultura Camponesa e da Reforma Agrária Popular, pautado na democratização da propriedade da terra; na resistência popular das famílias camponesas; na cooperação agrícola; na agroindustrialização do interior; na integração de tecnologias que respeitem a natureza; na agroecologia e no cuidado com as sementes; e na diversificação da produção de alimentos, e de um projeto de Educação do Campo vinculado a uma proposta popular, suas bandeiras de luta e sua construção. Do outro, o agronegócio da agricultura industrial; das transnacionais; das sementes transgênicas; da concentração da propriedade da terra; da destruição ambiental pelo alto consumo de agrotóxicos e desmatamento; do regime de integração dos agricultores familiares; e da monocultura extensiva. (MST-CE, 2009, p. 2).
\end{abstract}

Tais projetos conflitivos de campo resultam também em disputa de dois projetos de educação: educação rural no campo e educação do campo. 0 primeiro, no contexto da lógica de educação no país, desenvolveu-se ao longo de quase todo o século XX. Já o segundo projeto confronta esse modelo de educação, retomando o pensamento socialista e a educação popular,

[...] construindo desde a luta pelo direito à educação e a partir de diversas experiências educacionais vinculadas aos anseios e interesses da classe trabalhadora camponesa, uma Educação e uma Escola vinculada à sua realidade, ao projeto de classe da Agricultura Camponesa e à Reforma Agrária. (MST-CE, 2009, p. 3).

Fruto da luta em defesa da educação do campo, do Projeto da Agricultura Camponesa e da Reforma Agrária Popular e também das experiências do trabalho feito com os movimentos populares, entendidos como o lugar inicial de vivência de uma pedagogia que se origina na cultura popular e, na região Nordeste, território rico de cultura, diversidade e ainda berço da colonização exploratória capitalista no Brasil, que originou - e perpetua até os dias atuais - a exploração e a miséria e que abriga a maior população de uma região semiárida do mundo é que resultando da relevância da organização popular no campo, aconteceu no Ceará, em 2007, a primeira jornada de luta por educação e escolas do campo, durante o primeiro mandato do governador Cid Ferreira Gomes, aliado político da gestão petista então à frente do governo federal. Essa conjuntura política possibilitou o diálogo entre o poder estadual e o setor de educação do campo no Ceará, resultando no compromisso do então governador para a construção das escolas de ensino médio do campo em assentamentos de reforma agrária.

Tuteladas pelo Estado, as escolas construídas nos assentamentos de reforma agrária são portadoras de significados e significantes, desde a luta pela conquista do direito à educação até o processo de formação de coletividade vivenciado pelos sem-terra, no sentido de que escola não é sinônimo de educação, mas que ela tenha "uma identidade própria nas escolas do campo, com um projeto político e pedagógico que fortaleça novas formas de desenvolvimento no campo, baseadas na justiça social, na cooperação agrícola, no respeito à vida e na valorização da cultura camponesa" (MSTCE, 2009, p. 5). Ao se definir como "escola do campo, estamos assumindo um vínculo mais amplo com o destino do conjunto dos camponeses(as) ou dos trabalhadores(as) do campo" (MST-CE, 2009, p. 5), ou ainda uma escola que, ao se dizer: 
[...] escola de assentamento, ou de acampamento, estamos afirmando a necessária vinculação da escola com a realidade local e o desafio de participar efetivamente da solução de seus problemas. Ao dizer escola do MST, afirmamos a relação que a escola deve ter com a luta pela Reforma Agrária, que vai além das questões localizadas em cada assentamento. Ao dizer escola do campo, estamos assumindo um vínculo mais amplo com o destino do conjunto dos camponeses(as) ou dos trabalhadores(as) do campo, o que exige da escola que também leve novas questões à comunidade, ajudando em seu engajamento a um projeto mais amplo, histórico, de futuro. Em qualquer das expressões, $o$ de ou $o$ do pretendem-se afirmativos de uma identidade construída. Não basta ter escola no assentamento; ela tem que ser uma escola de assentamento. Não basta ter uma escola no campo; tem que ser uma escola do campo, que assuma as causas e a cultura de quem ali vive e trabalha. (MST-CE, 2009, p. 5).

Assim, vai sendo construída a escola do campo nos assentamentos de reforma agrária no estado do Ceará, uma escola com sentido amplo de educação, inicialmente com a conquista das escolas de ensino fundamental ainda na década de 1990 e, em 2007, com as escolas de ensino médio do campo, ano em que acontece o 5o Congresso Nacional do Movimento dos Trabalhadores Rurais Sem Terra (MST), em Brasília.

\begin{abstract}
No ano 2007, ocorreu o 5 Congresso Nacional do Movimento dos Trabalhadores Rurais Sem Terra - MST, em Brasília. Na ocasião, foi feita a solicitação pelo MST ao ministro da Educação, Fernando Haddad, da construção de 05 (cinco) escolas de educação do campo para o Estado do Ceará. Na época, o ministro se comprometeu com a construção das referidas escolas. Ainda no mesmo ano, o Movimento dos Trabalhadores Rurais Sem Terra - MST, mediante mobilização no palácio do governo do Estado do Ceará, solicitou ao governador Cid Ferreira Gomes a construção de cinco (05) escolas de educação do campo nos municípios de Itarema, Itapipoca, Madalena, Monsenhor Tabosa e Jaguaretama. Na época, o governador também se comprometeu com a construção das escolas. Mas essa realidade só veio a se concretizar de fato a partir do ano 2009. (MST-CE, 2009, p. $5)$.
\end{abstract}

A promessa do governo do Ceará foi de construir 20 escolas de ensino médio; dessas, 12 foram garantidas. A construção delas se inicia a partir de 2009 e se estende por 2010. Em 2011, começaram a funcionar as cinco primeiras escolas e duas iniciaram suas atividades em 2016. Duas estão sendo finalizadas, uma entrou em funcionamento em 2017 e três tiverem iniciados os processos de licitação e de construção. Atualmente, oito escolas estão em funcionamento: 1) EEM do Campo João dos Santos de Oliveira, no assentamento 25 de Maio, em Madalena; 2) EEM do Campo Florestan Fernandes, localizada no assentamento Santana, em Monsenhor Tabosa; 3) EEM do Campo Maria Nazaré de Souza, no assentamento Maceió, em Itapipoca; 4) EEM do Campo Francisco Araújo Barros, no assentamento Lagoa do Mineiro, em Itarema; 5) EEM do campo Padre José Augusto, situada no assentamento Pedra e Cal, Jaguaretama; 6) EEM do Campo Filho da Luta Patativa do Assaré, no Assentamento Santana da Cal, em Canindé; 7) EEM do Campo José Fidelis de Moura, que está localizada no assentamento Bonfim Conceição, em Santana do Acaraú; 8) EEM do Campo Francisca Pinto dos Santos, no assentamento Antônio Conselheiro em Ocara.

No Ceará, já é garantido o direito às escolas de ensino fundamental anos iniciais e finais na maioria dos assentamentos de reforma agrária, sendo também encontradas creches que asseguram a educação infantil nos primeiros anos de educação. A construção de oito escolas de ensino médio do campo em assentamentos de reforma agrária já é uma realidade. Destacamos ainda a formação superior, realizada através de convênios firmados a partir de programas e projetos em ações conjuntas entre as instituições de ensino superior federal e estadual com o PRONERA/INCRA.

Na luta pelo direito à educação no Ceará, as bases para a compreensão e o fortalecimento do processo de construção da educação do campo, em diferentes tempos históricos, foram fundamentais à 
sustentação legal das diretrizes nacionais para a educação do campo em 2002. Tais bases permitiram que o setor de educação do MST no Ceará mobilizasse os assentamentos de reforma agrária, dando início ao estudo e à análise dessas diretrizes, com a realização de seminários e encontros e, assim, permitindo desencadear a construção da luta por educação do campo e o processo de organicidade da escola. 0 espírito dos professores, dos assentados e do próprio setor de educação do campo foi o de se debruçar sobre a legislação para conhecer e, amparados pela base legal, fortalecer a luta por educação pública, gratuita e de qualidade de assentados e filhos de assentados nos diferentes níveis de ensino e nas diversas modalidades, em conformidade com as exigências das diretrizes curriculares nacionais.

No Ceará, os educadores da reforma agrária - em conjunto com o setor de educação do campo, apoiados pelo MST nacional, na luta em torno da construção da educação do campo - pautaram-se na busca por diálogo junto aos governos estadual e federal desde 1995 até entrar em funcionamento a primeira EEM do Campo. Tudo foi indispensável, bem como subsidiou a elaboração dos documentos que serviriam de orientação para a implantação e a realização de todo o processo de organização, gestão e desenvolvimento das atividades das escolas do campo. Assim, a formulação de um projeto políticopedagógico para as EEM do campo dos assentamentos de reforma agrária no Ceará, das diretrizes das escolas do campo e das diretrizes curriculares estaduais começa a ser pensada e produzida antes mesmo da inauguração das primeiras escolas.

Destarte, vai sendo construída a escola do campo nos assentamentos de reforma agrária no Estado do Ceará, uma escola com sentido amplo de educação, inicialmente com a conquista das escolas de ensino fundamental ainda na década de 1990 e, em 2007, com as escolas de ensino médio do campo, uma escola cuja realização da educação do campo é pautada em cinco princípios fundamentais: trabalho, cultura, pesquisa, historia e luta social, que auxiliados pelo projeto político-pedagógico, o currículo, as diretrizes curriculares nacional e estadual, as leis, os decretos e programas, enfrentamentos e desafios, paulatinamente no cotidiano da vida no campo está sendo construida, visto que na escola do campo, o trabalho é tratado como princípio educativo organizado para educar o ser humano para a vida em sociedade, para entender a realidade e transformá-la; é o trabalho socialmente útil, não alienado, qualificado para a melhoria da sua condição de vida, recorrendo ao conhecimento científico e empírico para compreender a totalidade dos processos globais, nacionais e nos territórios camponeses. Trabalho que complete o ser humano, que não seja um fardo, mas seja parte integrante de sua vida pessoal e profissional.

Em janeiro de 2011, realiza-se a primeira semana pedagógica das EEM do campo no Ceará, apoiada pelo governo do estado, por meio da Secretaria de Educação (SEDUC), pelas CREDES, pelo Setor de Educação do Campo do MST e pela Secretaria Municipal de Educação do município de Madalena, Ceará. O evento ocorre na EEM do Campo João dos Santos de Oliveira, no Assentamento 25, com a presença de representantes das entidades já mencionadas, dos/as educadores/as da educação básica das escolas que começariam a funcionar, de representantes de assentados, de cooperativas e de associações dos assentamentos de reforma agrária, além de representantes de instituições públicas de ensino superior do Ceará, estudantes, entre outros.

As semanas pedagógicas acontecem desde 2011, todos os anos, em janeiro, e contam com a participação de pessoas renomadas nacionalmente, bem como de referências regionais e estaduais de instituições de ensino superior e de outras instituições e entidades possuidoras de identidade com as questões agrárias, a luta social e a educação do campo. Todos contribuem de forma voluntária com conhecimento científico a partir de palestras com temas, pesquisas e experiências relacionadas às questões agrárias, educacionais, sociais que possam refletir sobre os problemas, limites, desafios e possibilidades relacionados aos conflitos do campo, à educação e à realidade brasileira no contexto da conjuntura política, econômica, social e ambiental.

As semanas pedagógicas em cada ano têm temáticas específicas, mas todos os anos são realizadas avaliações sobre as conjunturas política, econômica e social; sobre os processos ocorridos anualmente para o fortalecimento e a construção da educação do campo em escalas local e nacional; sobre os trabalhos desenvolvidos durante o ano pelas escolas do campo; além da organização do planejamento no âmbito das escolas de educação do campo dos assentamentos de reforma agrária do Ceará. 
Portanto, compreender os processos em construção sobre a educação do campo nos assentamentos de reforma agrária no Ceará demanda apreendê-los no interior da organicidade das escolas conquistadas. A luta dos/as educadores/as, estudantes, dos assentados e de comunidades busca estratégias de fortalecimento dos planejamentos coletivo e individual para a organização e a mobilização dos trabalhadores como um dos objetivos políticos da educação do campo.

Esse processo histórico da educação rural no Ceará foi marcado por continuidades e descontinuidades, entretanto, com as diretrizes curriculares nacionais publicadas em 2002, que dá nova redação, agora, no contexto da educação do campo, que certamente contribuiu para a organização e fortalecimento dos movimentos sociais na luta pela garantia de se ter educação de qualidade no campo, é que com a mobilização do setor de educação do MST no Ceará e com o trabalho de base realizado nos assentamentos se garantiu a conquista das escolas de nível médio do campo. Um enfrentamento permanente junto ao Estado e com o diálogo, foram sendo incorporadas, novas conquistas, tais como: o campo experimental em cada escola com área de 10 hectares, a parte diversificada do currículo, o técnico agrônomo para cada escola, acompanhamento pedagógico pago com recursos do Estado, etc. Em dezembro de 2012, dez anos após publicação das diretrizes por meio de reunião entre a SEDUC/CODEA e Setor de Educação do Campo do MST, UFC, Federação dos Trabalhadores Rurais Agricultores e Agricultoras Familiares do Estado do Ceará- FETRAECE, formalizou-se o debate para dar início à construção das diretrizes estaduais de educação para o ensino médio no Ceará.

Segundo documentos registados pela CODEA, versão preliminar do texto das diretrizes foi elaborada nos meses de janeiro e fevereiro de 2013. Entretanto, conflitos de interesses entre educadores do MST e SEDUC geraram impasses no âmbito dessas instituições o que conduziu a não conclusão e não publicação das diretrizes estaduais para as escolas do campo no Ceará.

Neste contexto, destaca-se ainda o papel do que diz respeito a garantia de recursos financeiros para a realização das semanas pedagógicas e dos encontros estaduais de educadores e educadoras do campo, enfatiza-se ainda, que as semanas pedagógicas das escolas de ensino médio do campo acontecem anualmente e reúnem durante 5 dias em geral no mês de janeiro, em uma das escolas todos os educadores(as). Garantindo também, a vinda de intelectuais de várias instituições brasileiras locais, regional e nacional, a construção de mais três escolas de nível médio, construção de vestiários e mais banheiros, cisternas. Em meio aos limites, conquistas, impasses e conflitos são avanços significativos, destacando-se ainda, em 2016 a seleção específica para contratação temporária de educadores (as) das escolas em assentamentos de reforma agraria e, em 2017, a primeira seleção pública de gestores, com edital específico escolas do campo: indígenas, quilombolas e de assentamentos de reforma agrária.

Assim, nas diretrizes estaduais de educação do campo, para além de um documento formalmente construído, existem sujeitos históricos e políticos envolvidos nessa luta, sendo duas as reinvindicações importantes do movimento: que a construção das diretrizes seja realizada com a participação de representações dos povos do campo, como os assentados da reforma agrária, os quilombolas e indígenas e, também, que as escolas do campo em assentamentos possuam um marco legal que garanta sua especificidade como escola diferenciada.

Durante esse período de uma década, que iniciou de maneira concreta com a conquista das escolas de ensino médio do campo até o ano de 2017, muitos desafios foram superados e houve muitas conquistas. Entretanto, não podemos nunca esquecer que a educação do campo é um projeto em disputa permanente e em movimento, e ainda, no âmbito do estado do Ceará vem possibilitando uma territorialização da pedagogia do Movimento Sem Terra. Atualmente, de maneira pontual, em oito assentamentos de reforma agrária onde, por meio da luta por educação, o movimento conquistou escolas do campo de nível médio e, através dessas escolas, o MST possibilita conquistas, avanços e desafios juntamente com os/as educadores/as da Reforma Agrária.

\section{3 - Considerações finais}

Muitas pautas de luta já foram conquistadas, mas a disputa e o conflito de classes no sistema capitalista vigente nunca se esgotam. São necessários organização, mobilização e contínuas estratégias para se avançar nas conquistas dos direitos fundamentais à vida do ser humano, no direito à educação 
do campo. A construção coletiva é carregada de significados na visão dos camponeses, como o de uma vida digna e de uma sociedade mais justa e com menos desigualdades.

Destarte, no contexto dos objetivos políticos na construção da educação do campo, a mobilização dos/as educadores/as, dos/as estudantes, dos/as assentados/as e das comunidades dos assentamentos de reforma agrária foi fundamental para a participação e a luta "por uma educação do campo" e uma escola diferenciada que possa ser assegurada e disposta nas diretrizes estaduais para a educação das escolas do campo do estado do Ceará. Uma escola pública que seja, por excelência, da classe trabalhadora.

\section{Referências}

BRASIL. Decreto no 7.352, de 4 de novembro de 2010. Dispõe sobre a Política Nacional de Educação do Campo e sobre o Programa Nacional de Educação na Reforma Agrária. Diário Oficial [da] República Federativa do Brasil, Poder Executivo, Brasília, DF, 5 nov. 2010.

BRASIL. Lei no 9.394, de 20 de dezembro de 1996. Estabelece as Diretrizes e Bases da Educação Nacional. Diário Oficial [da] República Federativa do Brasil, Poder Executivo, Brasília, DF, 21 dez. 1996.

BRASIL. Programa Nacional de Educação na Reforma Agrária (PRONERA). Brasília- DF, 2016.

CALDART, Roseli Salete. Educação do campo. In: CALDART, Roseli Salete et al. (Org.). Dicionário de educação do campo. Rio de Janeiro/São Paulo: Expressão Popular, 2012. p. 257-265.

CALDART, Roseli Salete. Sobre educação do campo. In: SANTOS, Clarice Aparecida (Org.). Por uma educação do campo: Campo - Políticas públicas - Educação. Brasília: Ingra/MDA, 2008. p. 67-86.

FERNANDES, Bernardo Mançano; MOLINA, Mônica Castagna. O campo da educação do campo. In: MOLINA, Mônica Castagna; FERNANDES, Bernardo Mançano (Org.). A educação na reforma agrária em perspectiva: uma avaliação do programa nacional de educação na reforma agrária. São Paulo: Ação Educativa; Brasília, DF: PRONERA, 2004. p. 32-53.

FREITAS, Katia Pinheiro de. Formação de educação de jovens e adultos do campo: produções do período 2006-2011. 2013. 157 f. Dissertação (Mestrado em Educação) - Programa de Pós-Graduação em Educação, Universidade Federal de Viçosa, Viçosa, 2013.

FREIRE, Paulo. Pedagogia do oprimido. 27. ed. Rio de Janeiro: Paz e Terra, 1987.

KOLLING, Edgar Jorge; VARGAS, Maria Cristina; CALDART, Roseli Salete Caldart. MST e Educação. In: CALDART, Roseli Salete Caldart et al. (Org.). Dicionário de educação do campo. Rio de Janeiro/São Paulo: Expressão Popular, 2012. p. 502-509.

MOLINA, M. C. Educação do campo e pesquisa: questões para reflexão. Brasília, DF: Ministério do Desenvolvimento Agrário, 2006.

MST - Movimento dos Trabalhadores Rurais Sem Terra. Caderno de trabalho de base do setor de educação do MST-CE. № 01. Organizando a estratégia de implementação das escolas do campo do MST. Agosto de 2009.

ORSO, Paulino José. A educação na sociedade de classes: possibilidades e limites. In: ORSO, Paulino José et al. (Org.). Educação e luta de classes. 2. ed. São Paulo: Expressão Popular, 2013. p. 49-63. 
STÉDILE, João Pedro; FERNANDES, Bernardo Mançano. Brava Gente: a trajetória do MST e a luta pela terra no Brasil. 2. ed. São Paulo: Expressão Popular: Perseu Abramo, 2012. 